\title{
PIM Kinase as an Executional Target in Cancer
}

\author{
Xinning Zhang ${ }^{1, *}$, Mengqiu Song ${ }^{2,3, *}$, Joydeb Kumar Kundu ${ }^{4}$, Mee-Hyun Lee ${ }^{2,3}$, Zhen-Zhen Liu ${ }^{1}$ \\ 'Department of Breast Surgery, Breast Cancer Center, Affiliated Cancer Hospital of Zhengzhou University, Henan Cancer Hospital, ${ }^{2}$ Basic Medical \\ College, Zhengzhou University, ${ }^{3}$ China-US (Henan) Hormel Cancer Institute, Zhengzhou, China, ${ }^{4}$ Department of Medical Microbiology and \\ Immunology, University of Alberta, Edmonton, $A B$, Canada
}

PIM (proviral integration site for moloney murine leukemia virus) kinase plays a key role as an oncogene in various cancers including myeloma, leukemia, prostate and breast cancers. The aberrant expression and/or activation of PIM kinases in various cancers follow an isoform-specific pattern. While PIM1 is predominantly expressed in hematological and solid tumors, PIM2 and PIM3 are largely expressed in leukemia and solid tumors, respectively. All of PIM kinases cause transcriptional activation of genes involved in cell survival and cell cycle progression in cancer. A variety of pro-tumorigenic signaling molecules, such as MYC, p21 Cip1/Naf1/p2 $7^{\text {kip }}$, CDC25, Notch1 and BAD have been identified as the downstream targets of PIM kinases. So far, three kinds of adenosine triphosphate-competitive PIM inhibitors, SGI-1776, AZD1208, and LGH447 have been in clinical trials for the treatment of acute myelogenous leukemia, prostate cancer, lymphoma, or multiple myeloma. This review sheds light on the signaling pathways involved in the PIM kinase regulation and current status of developing PIM kinase inhibitors as clinical success in combating human cancer.

(J Cancer Prev 2018;23:109-116)

Key Words: Proto-oncogene proteins PIM kinase, PIM signaling pathways, PIM kinase inhibitor

\section{INTRODUCTION}

The PIM kinases, which constitute a class of serine/threonine kinase, act as oncoproteins and promote cell survival by transcriptional activation of genes involved in cell proliferation. ${ }^{1}$ The family of PIM kinase consists of three isoforms, PIM-1, PIM-2, and PIM-3. Each of the PIM kinases plays an important role in tumorigenesis. While PIM-1 has been reported to be overexpressed in several hematological and solid tumors PIM-2 is highly expressed in myeloma, lymphoma and leukemia. The elevated expression of PIM-3 has been noted in adenocarcinomas. Diverse roles that the PIM kinases play in carcinogenesis include multiple myeloma proliferation, antiapoptosis, cell cycle modulation, and mediating bone destruction., ${ }^{2.3}$ PIM kinases could inhibit apoptosis and promote cell cycle progression in prostate cancer and their overexpression relates to the grade and neoplastic transformation. ${ }^{4}$ The overexpression of PIM-1 in breast cancer is related to poor prognosis in HER2- and hormone-negative tumors. ${ }^{5}$ Taken together, PIM kinases play an important role in tumorigenesis, but the mechanism is currently unclear. Here we discuss the signaling mechanisms underlying PIM kinases in tumorigenesis and opportunities for targeting PIM kinases as a treatment for cancer therapy.

Received April 4, 2018, Revised April 25, 2018, Accepted April 30, 2018

Correspondence to: Zhen-Zhen Liu

Affiliated Cancer Hospital of Zhengzhou University, Henan Cancer Hospital, No. 127, Dongming Road, Jinshui District, Zhengzhou, 450008, China Tel: +86-136-0386-2755, Fax: +86-371-65588134, E-mail: liuzhenzhen73@163.com, ORCID: Zhen-Zhen Liu, https://orcid.org/0000-XYZQ-ABCD-EFGH Correspondence to: Mee-Hyun Lee

China-US (Henan) Hormel Cancer Institute, No. 127, Dongming Road, Jinshui District, Zhengzhou, Henan, 450008, China

Tel: +86-371-65587008, Fax: +86-371-65587670, E-mail: mhlee@hci-cn.org, ORCID: Mee-Hyun Lee, https://orcid.org/0000-0002-5141-1112

$*$ These authors contributed equally to this work as co-first authors.

Copyright (C) 2018 Korean Society of Cancer Prevention

(c) This is an Open Access article distributed under the terms of the Creative Commons Attribution Non-Commercial License (http://creativecommons.org/icenses/by-nc/4.0) which permits unrestricted non-commercial use, distribution, and reproduction in any medium, provided the original work is properly cited. 


\section{PIM KINASE FAMILY MEMBERS}

In the 1980s, the locus of PIM kinase gene in chromosome occur the proviral insertion for activation of PIM kinase gene transcription and PIM kinase gene was found in murine leukemia virus-induced lymphoma. ${ }^{6}$ The overexpression of PIM kinases is associated with a poor prognosis in prostate cancer, establishing the prognostic potential of PIM kinases in cancer. ${ }^{7}$ PIM-1 had significantly lower expression in benign prostatic epithelium than in prostate adenocarcinoma, suggesting that PIM-1 may be a potential biomarker for distinguishing between nonmalignant and malignant prostate tissues. ${ }^{4,8}$ Recently, it has revealed that tissues with PIM-1 overexpression have a worse prognosis compared to other cancers, such as breast cancers. ${ }^{5}$ However, the mechanism underlying PIM-1 kinase expression and the treatment and prognosis of human cancers has poorly understood. Thus, it has become an area of increasing interest and a promising therapeutic cancer target.

PIM-2 shares similar oncogenic functions with PIM-1 and highly homologous to PIM-1 kinase. ${ }^{9}$ PIM-2 has three isoforms, PIM-2S, PIM-2M, and PIM-2L. PIM-2 expression decreases the sensitivity of cells to a variety of apoptotic stimuli and responds negatively to growth factor withdrawal. ${ }^{10}$ As an important pro-survival gene, PIM-2 expression has also been observed to be significantly increased in cancers. ${ }^{8}$

PIM-3, alternatively known as Kid-1, has been characterized as a depolarizing protein in PC-12 cells. ${ }^{11}$ The PIM-3 gene sequence shows highly similarity in the kinase domain and deficient regulatory domains of the PIM-1. Similar to other family members, PIM-3 kinase has very important functions in cell apoptosis and the cell cycle. ${ }^{12}$ Abnormal expression of PIM-3 has been reported in different types of cancer, such as liver cancer, ${ }^{13}$ pancreatic cancer, ${ }^{14}$ colon cancer, ${ }^{15}$ and gastric cancer. ${ }^{16}$ Knockdown of PIM-3 by small interfering RNAs reduced human hepatoma cell proliferation demonstrating the important function of PIM-3 in tumor progression. ${ }^{13}$

\section{CELLULAR TARGETS OF PIM KINASES}

PIM kinases are involved in downstream physiological pathways via phosphorylating many cellular substrates, for example, transcriptional modulators including myelocytomatosis (MYC); cell cycle modulators including p21 ${ }^{\text {Cip1/Waf1 }}$ (CDKN1A), p27KIP1 (CDKN1B), and cell division cycle 25A (CDC25A) and 25C (CDC25C); signaling intermediates such as Notch homolog 1 , translocation-associated (Notch1); and apoptosis modulators such as BCL-2-associated agonist of cell death (BAD) (Fig. 1).

\section{MYC}

MYC is an import transcription factor that regulates cellular processes, such as cell proliferation, microRNA regulation, cell metabolism and anti-apoptosis via inappropriate activation and/or inhibition of various signaling pathways. ${ }^{17}$ Among the PIM kinases, especially PIM-1 and PIM-2 have a close relationship with MYC as a collaborating partner in tumorigenesis. ${ }^{18}$ MYC is phosphorylated at Thr-58 and Ser-62 of the N-terminal domain by PIM kinases. Moreover, PIM-1 and PIM-2 phosphorylate MYC at Ser-62 and Ser-329, respectively, thereby increasing the stability of MYC protein and enhancing MYC transcriptional activity for targeting E2F2 and nucleolin. ${ }^{19}$ MYC contains basic helix-loophelix zipper (bHLHZ) domain that heterodimerizes with the small bHLHZ protein MYC-associated factor X (MAX), and then binds with the E-box sequence. PIM-1 forms a complex with the MYC-MAX heterodimer via the MYC Box II (MBII) domain. ${ }^{20}$ MYC could recruit PIM-1 to E-boxes by a direct protein-protein interaction, allowing PIM-1 to phosphorylate Histone H3 on Ser10 (H3S10), contributing to transcriptional activation (Fig. 2). ${ }^{21}$

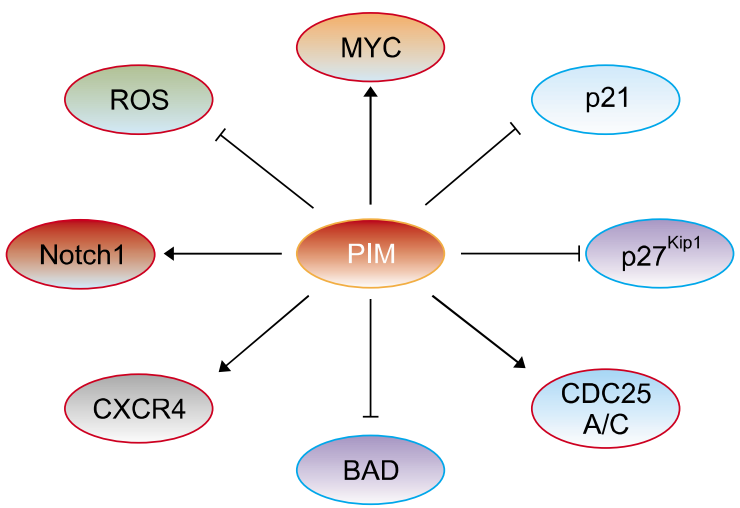

Figure 1. The substrates of PIM (proviral integration site for moloney murine leukemia virus) kinase. PIM activates genes transcription and cell cycles, and inhibits apoptosis of cells by directly or indirectly regulation of targets. PIM directly phophorylates myelocytomatosis (MYC) (Ser62/Ser329), cell division cycle 25A (CDC25A), and Notch homolog 1, translocation-associated (Notch1) (Ser2152) for triggering transcriptional activation and cell cycles to promoting cancer cell proliferation. Phosphorylation by PIM also inactivates p21 ${ }^{\text {Cip1/Waf1 }}$ (Thr145)/p27 $7^{\text {Kip1 }}$ (Thr157) and BCL-2-associated agonist of cell death (BAD) (Ser112) for prohibiting cell cycle regulation and apoptosis. PIM possibly phosphorylates C-X-C chemokine recepter type 4 (CXCR4) thereby enhances chronic lymphocytic leukemia cell survival, and decreases reactive oxygen species (ROS) by regulation of Nrf2 in the hypoxic tumor cells. 


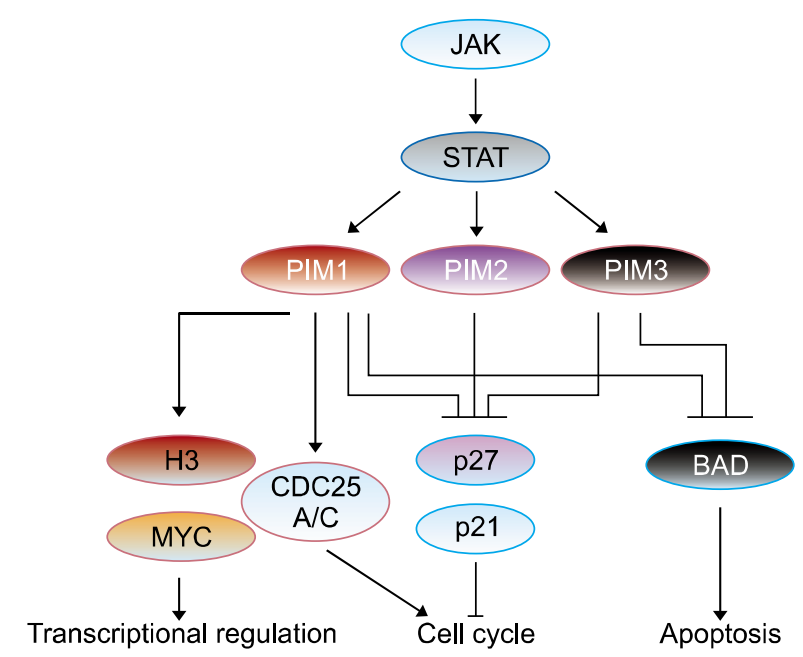

Figure 2. Signaling pathways involving PIM kinase. Up-stream target proteins of PIM (proviral integration site for moloney murine leukemia virus) kinase are janus kinase/signal transducers and activators of transcriptions (JAK/STATs) and their activations cause to stimulate PIM kinase. Activated PIM kinase boosts its downstream signaling targets, such as myelocytomatosis (MYC), BCL-2-associated agonist of cell death (BAD), p2 $1^{\text {Cip1/Waf1 }} / \mathrm{p}^{2} 7^{\text {Kip1 }}$, and cell devision cycle 25 (CDC25), and regulates gene transcription, cell cycle progression, and apoptosis.

\section{2. $\mathrm{p} 21^{\mathrm{Cip} 1 / \text { Waf1 }}$ and $\mathrm{p} 27^{\mathrm{kip} 1}$}

PIM kinases play a key role in the cell cycle regulation via influencing p21 ${ }^{\text {Cip1/Naf1 }}, \mathrm{p}^{\text {Kip1 }} 7^{\text {, and CDC25A/C. The p21 }}{ }^{\text {Cip1/Waf1 }}$, a tumor suppressor protein, ${ }^{1}$ acts as an inhibitor of cell cycle progression. p21 $1^{\text {Cip1/Naf1 }}$ combines with cyclins and cyclindependent kinases (CDKs), forming heterotrimeric complexes. ${ }^{22}$ In association with $\mathrm{CDK} 2$ complexes, it can decrease the kinase activity and inhibit the cell cycle at G1/S phase transition. p21 $1^{\text {Cip1/Naf1 }}$ may also be involved in the assembly of $\mathrm{CDK} 4 / \mathrm{CDK} 6$ and cyclin D, and regulating the catalytic activity of CDKs. PIM-1 can phosphorylate $\mathrm{p} 21^{\text {Cip/Nafl }}$ at Thr-145 to influence the cell cycle and thereby contribute to promoting cell proliferation by affecting the cellular localization and stability of p21 ${ }^{\text {Cip1/Nafl } 123}$ p2 $7^{\text {Kip } 1}$ belongs to the Cip/Kip family and it has similar function with p21 ${ }^{\text {Cip1/Naf1 }} \cdot$ p2 $7^{\text {Kip1 }}$ arrests cell cycle at the G1 phase via inhibitory binding to $\mathrm{CDK} 2 /$ cyclin $\mathrm{E}$ or other $\mathrm{CDK} /$ cyclin complexes. ${ }^{22} \mathrm{PIM}$ kinases prompt its binding to $14-3-3$ proteins by phosphorylating $\mathrm{p} 27^{\mathrm{Kip} 1}$ at $\mathrm{Thr}-157$ and Thr-198, leading to nuclear exclusion and degradation of p27.12,16 PIM kinases mediate phosphorylation and inactivation of fork-head transcription factors, FOXO1a and FOXO3a, which are involved in $p 2{ }^{K i p 1}$ transcriptional repression. ${ }^{24}$ PIM kinases participate in tumorigenesis and cell cycle progression through downregulating p2 $7^{\mathrm{Kip} 1}$ expression at both of the transcriptional and posttranslational levels (Fig. 2).

\section{3. $C D C 25 A / C$}

The CDC25 protein family is involved in the activation of CDKs via de-phosphorylation at conserved Thr-14/Tyr-15 inhibitory phosphorylation sites. ${ }^{25} \mathrm{CDK} 2$ is the primary substrate of CDC25A and its activation allows progression through the G1/S and intra-S checkpoints. CDC25A exerts its activity via a variety of mechanisms, for example, ubiquitination, phosphorylation, and inhibitory binding to $14-3-3$ proteins. ${ }^{26}$ PIM-1 kinase can directly interact and phosphorylate CDC25A, thereby enhancing CDC25A phosphatase activity. On the other hand, PIM-1 activates c-Myc-mediated apoptotic signaling by upregulating $\mathrm{CDC} 25 \mathrm{~A}$ (Fig. 2). It has been reported that both c-tat-associated kinase (TAK1) and checkpoint kinase (CHK) $1 / 2$ phosphorylate $\mathrm{CDC} 25 \mathrm{C}$ at Ser216 in the DNA damage response and regulate the G2/M checkpoint of the cell cycle. ${ }^{26}$ Thus, as a substrate of PIM-1, the inhibition of CDC25C by PIM-1 would arrest cell cycle at G2/M phase transition.

\section{Notch}

Notch proteins have four isoforms: Notch1, 2, 3, and 4; they belong to a family of transmembrane receptors. Notch activity affects cell differentiation, proliferation, and apoptotic processes, furnishing a general tool to influence cellular mechanism, such as organ formation and morphogenesis. ${ }^{27.28}$ Notch signaling plays an important role in tumor progression and is frequently deregulated in malignancies. It has been reported that high expression of Notch1 caused epithelial-to-mesenchymal transition which corroborates to the poor prognosis, and increased glycolytic metabolism in breast cancer. ${ }^{27}$ All PIM kinases can phosphorylate Notch 1 at Ser-2152 and enhance the transcriptional activity and nuclear localization of the Notch1 intracellular domain in breast and prostate cancer cells. ${ }^{28}$

\section{BAD}

$\mathrm{BAD}$ is a pro-apoptotic member of the B-cell lymphoma (Bcl)-2 family that promotes cell death by displacing Bax from binding to Bcl-2 and B-cell lymphoma-extra large (Bcl-xL). ${ }^{29}$ Various cell survival factors can phosphorylate BAD at Ser-112/Ser-136 and Ser-155 via activating intracellular signaling pathways to inhibit the apoptotic activity of BAD. Only the non-phosphorylated BAD heterodimerizes with $\mathrm{Bcl}-\mathrm{xL}$ at membrane sites to promote cell death. ${ }^{30}$ Phosphorylation at these sites after binding with BAD promotes the binding of Bad to 14-3-3 proteins, thus preventing 
the association between Bad with Bcl-2 and Bcl-xL. ${ }^{31}$ PIM-1 phosphorylates Bad at Ser-112, which is an executional site for its inactivation, enhancing Bcl-2 activity and promoting cell survival (Fig. 2). ${ }^{32}$ PIM-2 has three isoforms, and the short one (PIM-2S [34 $\mathrm{kDa}$ ) has strongest function in enhancing cell survival. ${ }^{33}$ PIM-2 can also phosphorylate the pro-apoptotic protein BAD on Ser-112, which accounts in part for its ability to reverse BAD-induced cell death. ${ }^{34}$ It also suggests that it has a high homology with PIM-1. Interestingly, the same function is also present in PIM-3 kinase. Some reports have suggested that PIM-3 can inhibit BAD by phosphorylating Ser-112 site in human cancer cells, for example, colon cancer and pancreatic cancer cells, and thus may attenuate apoptosis and promote progression of cancer. ${ }^{15,34}$

\section{ROLES OF PIM KINASES IN CANCER SIGNALING PATHWAYS}

Serine/threonine kinases and their phosphorylated forms play critical roles in a wide range of biological processes, such as tumorigenesis. Each phospho- (serine/threonine) kinase phosphorylates serine or threonine within a specific motif. Both the PIM family and protein kinase $b$ (PKB)/AKT family belong to the serine/threonine protein kinases family and both play important roles in cancer development. ${ }^{35}$ PIM kinases have constitutive activity, and the half-lives of their mRNA and proteins are relatively short. EPH-like tyrosine kinase (ETK) phosphorylates PIM-1 at the Thr-218 residue, and this process is involved in the interlukin (IL)-6-induced activation of androgen-mediated transcription. Furthermore, protein phosphatase 2 (PP2A) can decrease the stability of PIM kinases. ${ }^{36}$ This illustrated the relevance between this phosphorylation and PIM activity, although it occurred in either autologous or heterologous manner. PIM proteins have reported to consist of more than 30 potential recognition sequences of different kinases.

PIM genes are rapid response genes which are induced upon exposure to mitogenic stimuli including interleukins, granulocytecolony stimulating factor, granulocyte-macrophage colonystimulating factor, and interferons. PIM kinases participate in the janus kinase/signal transducers and activators of transcription (JAK/STAT) pathways. JAK and STAT proteins are activated by the binding of cytokines and growth factors with their cognate receptors, and the amplification of JAK-STAT signaling promotes tumor progression, cell motility, angiogenesis, immune responses, and stem cell differentiation. ${ }^{9}$ Upon cytokine exposure, JAK kinase phosphorylates the cytoplasmic receptor domain of cytokine receptors and recruits STAT proteins. Subsequent phosphorylation of STATs by JAK leads to the dimerization and nuclear translocation of STAT. In the nucleus, activated STATs transcribe target gene expression by binding to specific promoter regions. For example, STAT3/STAT5 binds to the promoter region of PIM-1 and initiates transcription for PIM-1 gene expression. ${ }^{37}$ PIM-1 works as a negative feedback regulator of the JAK/STAT5 pathway by interaction with suppressor of cytokine signaling (SOCS) proteins in hematopoietic cells. ${ }^{38} \mathrm{PIM}-1$ also contributes to tumorigenesis through the regulation of transcriptional activities of MYC translation of cap-dependent protein, and cell cycle progression. ${ }^{18,19,39}$ The control of survival signals by PIM-1 has mainly regulated by the phosphorylation of $\mathrm{BAD}$ protein. In myeloma, stromal-derived factors, like IL-6 or the TNF family of cytokines, regulate PIM-2 via NF-кB signaling pathways and it plays an important role in myeloid leukemia cell survival and stress adaptation. Furthermore, PIM-1 and PIM-2 have been reported to be upregulated by the activation of NF- $\mathrm{BB}$ or homeobox protein HoxA9 in response to Fms-like tyrosine kinase/internal tandem duplication, mixed-lineage leukemia or myeloid-lymphoid leukemia (MLL)-X, and MLL-partial tandem duplication oncogenic mutants. For PIM-3 gene expression, the promoter region contains one NF-B, two Sp1, and two Ets-1 binding sites as well as a binding site for STAT3. ${ }^{40}$ PIM-1 kinase synergistically induces STAT3-mediated cell cycle progression and anti-apoptotic phenomenon. Popivanova et al. ${ }^{15}$ have demonstrated that PIM-3 might also synergistically enhance the malignant phenotype induced by STAT3-mediated signals in colon cancer. For the regulation of PIM expression, mi-R1 and mi-R210 microRNAs could control transcriptional gene levels of PIM-1 in tumors. ${ }^{41}$

\section{PIM KINASES ACT AS THERAPEUTIC TARGETS}

PIM kinases received much attention for anticancer drug development since they have aberrantly expressed in distinct cancer types. Some small molecule inhibitors directly targeting the adenosine triphosphate (ATP)-binding domain of PIM proteins have been developed and already been well-researched for getting into clinical trials (Table 1).

SGI-1776, the first PIM-1 inhibitor that targets all three PIM kinases, has been tested in clinical trials in non-Hodgkin lymphoma and prostate cancer patients. Chen et al. ${ }^{42}$ found that SGI-1776 suppressed acute myeloid leukemia (AML) by reducing Mcl-1 transcription activity, which is part of the $\mathrm{Bcl}-2$ anti-apoptotic family. Two clinical trials of SGI-1776 have been carried out and both sponsored by Astex Pharmaceuticals 
Table 1. PIM kinase inhibitors in clinical trials

\begin{tabular}{|c|c|c|c|c|c|}
\hline Drug & Structure & $\begin{array}{c}\text { Phase of } \\
\text { development }\end{array}$ & $\begin{array}{l}\text { Clinical trial } \\
\text { identification }\end{array}$ & Targets & Disease \\
\hline AZD1208 & & Phase I & $\begin{array}{l}\text { NCT01489722 } \\
\text { NCT01588548 }\end{array}$ & $\begin{array}{l}\text { Kd: } \\
\text { PIM1: } 0.2 \mathrm{nM} \\
\text { PIM2: } 0.88 \mathrm{nM} \\
\text { PIM3: } 0.76 \mathrm{nM}\end{array}$ & $\begin{array}{l}\text { Acute myelogenous } \\
\text { leukemia (AML) }\end{array}$ \\
\hline SG1-1776 & & Phase I & $\begin{array}{l}\text { NCT00848601 } \\
\text { NCT01239108 }\end{array}$ & $\begin{array}{l}\mathrm{IC}_{50} \text { : } \\
\text { PIM1: } 7 \mathrm{nM} \\
\text { PIM2: } 363 \mathrm{nM} \\
\text { PIM3: } 69 \mathrm{nM}\end{array}$ & $\begin{array}{l}\text { Refractory prostate } \\
\text { and lymphoma }\end{array}$ \\
\hline LGH447 & & Phase I/II & $\begin{array}{l}\text { NCT02160951 } \\
\text { NCT02144038 } \\
\text { NCT02078609 } \\
\text { NCT02370706 } \\
\text { NCT01456689 }\end{array}$ & PIM1/2/3 & $\begin{array}{l}\text { Multiple myeloma } \\
\text { Relapsed and refractory } \\
\text { multiple myeloma } \\
\text { AML and high risk } \\
\text { MDS myelofibrosis } \\
\text { Multiple myeloma }\end{array}$ \\
\hline
\end{tabular}

MDS, myelodysplastic syndrome.

(NCT00848601, NCT01239108). The first one was withdrawn prior to enrollment because it showed dose-limiting toxicity in cardiac electrical cycle (QTc) prolongation. The second one has terminated in the phase I study in patients with refractory prostate cancer and lymphoma because of its toxicity on cardiac QTc prolongation.

AZD1208, a pan-PIM kinase inhibitor, showed antitumor effects by acting on multiple pathways, such as apoptosis, proliferation, translation, and vesicular transport. Kreuz et al. ${ }^{43}$ and Kirschner et al. ${ }^{44}$ reported that AZD1208 treatment leads to decrease proliferation of non-Hodgkin lymphoma cell lines and prostate cancers by inhibiting PIM kinase activities and MYC mediated activities, as evaluated by knock-down of PIM or RNA-sequencing and microarray analysis. The safety, tolerability, efficacy, and pharmacokinetics of AZD1208 have been evaluated by clinical trials in AML patients and advanced solid malignancies (NCT01489722, NCT01588548, AstraZeneca). The global phase I study to assess the safety and tolerability of AZD1208 in malignant lymphoma and advanced solid tumors has been completed in October 2015. The results showed that AZD1208 has been tolerated up to $700 \mathrm{mg}$ and induced CYP3A4 activity, and the mean half-life after treatment with a single dose was $\sim 37.2$ hours (minimum 18.9 hours; maximum 103 hours). ${ }^{45}$ Although they failed to find the clinical significance, some of patients observed the decrease of pBAD Ser-112 expression and prostate-specific antigen in AML or prostate cancer patient samples.

LGH447 is an orally bioavailable small-molecule inhibitor of the PIM kinases with activity against all three PIM isoforms. ${ }^{2}$
LGH447 interrupts G1/S cell cycle transition and affects the expression of different pro-apoptotic proteins such as Bcl-2 by inhibiting PIM kinase activities. In PIM-2-dependent multiple myeloma, LGH447 application significantly decreased cell proliferation and mTOR-C1 signaling in mouse subcutaneous xenograft models. ${ }^{46}$ Raab et al. ${ }^{47}$ carried out the first-in-human phase I dose-escalation study on LGH447 in 54 patients with relapsed/refractory multiple myeloma. LGH447 single-treatment activity was dominant at doses $>150 \mathrm{mg}$ among the 48 evaluable patients, and the other five patients (11\%) had partial or better responses at doses ranging from 150 to $500 \mathrm{mg}$. This study indicated that LGH447 has a potential therapeutic role in multiple myeloma patients.

Even though PIM protein has been overexpressed in various kinds of cancer, it still considered as "weak" oncoproteins because they require an accompanying oncoprotein to exert their tumorigenic properties. Thus, trial of the combination therapy along with PIM inhibitors and chemotherapeutic drugs has led to a remarkable progress.

Pan-PIM inhibitor AZD1208 and dual-mTORC1/2 inhibitor AZD2014 combination has firstly performed in AML. This combination therapy was demonstrated to successfully arrest protein synthesis and induce mitochondria-mediated apoptosis through simultaneous inhibition of the mTORC1/2 pathway and synergistically attenuated AML growth by effectively suppress heat shock factor pathway by uncovering the master negative regulation of heat shock factor 1 (HSF1). ${ }^{48}$ Thus, it appears as an attractive approach to combine PIM kinase inhibitors with other 
oncoprotein inhibitors in designing new cancer therapy.

Similar combination trial has ever tried in mantle cell lymphoma (MCL). As a potent and selective PIM kinase inhibitor, SGI-1776 has considered to combine with an alkylating agent, bendamustine, to solving its cytotoxicity showed on Phase II clinical trial in MCL and CLL. SGI-1776 and bendamustine combination therapy showed augmented cellular response compared to single agent treatments in respect of promoting DNA damage response and DNA, RNA and protein synthesis as well as inducing apoptosis. ${ }^{49}$

Apart from the synthetic compounds, some natural fractions and small molecule inhibitors could also attenuate cell growth and inhibit tumorigenesis via targeting PIM kinase.

Quercetagetin was a special inhibitor of PIM-1 kinase with an $\mathrm{IC}_{50}$ of $0.34 \mu \mathrm{mol} / \mathrm{L},{ }^{50}$ and its administration effectively attenuated PIM-1 activity in nasopharyngeal carcinoma cells, decreased cell proliferation and migration. ${ }^{51}$ Compared to other serine-threonine kinase families, quercetagetin showed better affinity to PIM-1 (9to 70-fold higher) than RSK2, PKA, and PIM-2. ${ }^{50}$

Hispidulin is a natural flavone extract from plants of the Asteraceae with a broad spectrum of biological activities. Hispidulin was identified as a PIM-1 specific inhibitor with an $\mathrm{IC}_{50}$ of $2.71 \mu \mathrm{M}^{52}$ Hispidulin was reported to exert antitumor activity in colorectal cancer cell lines and xenograft animal model as evidenced by inhibition of cell growth, invasion and induction of apoptosis. Moreover, the compound can also repress the expression of PIM1 by suppressing JAK2/STAT3 signaling through the generation of reactive oxygen species. ${ }^{53}$

\section{PERSPECTIVES}

PIM kinases have been well studied as a potential therapeutic target for developing anti-cancer drugs due to their pivotal roles in cancers. Till to date, most of the PIM kinase inhibitors that undergone clinical trials have been developed as pan-specific ATP binding agents. In addition to these drugs, some natural compounds, such as hispidulin, can potentially suppress tumor growth by inhibiting PIM kinases. Hispidulin induced mitochondrial-mediated apoptosis and suppressed the P13K/AKT signaling pathway in HepG2 cells, suggesting that hispidulin maybe developed as a therapeutic agent of liver cancer. ${ }^{54}$ It has been reported that single nucleotide polymorphisms in the PIM-1 gene are correlated with increased risk of lung cancer in Korean patients. ${ }^{55}$ Overexpression of PIM-2 kinase in AML patients was knocked-down by PIM-2 RNAi and strongly reduced the accumulation of oncogenic proteins. PIM-3 has also reported in
B-cell lymphomas. ${ }^{56}$ Because of the expression of PIM kinases by oncogenic JAK-STAT signaling cascades and the pivotal role of PIM kinases in regulating MYC-transcription factor mediated cell cycle progression, designing novel class of PIM kinase inhibitors and evaluating their efficacy in controlled clinical trials would lead to generation of new anticancer drugs.

\section{ACKNOWLEDGMENTS}

This work was supported by grant funding from the National Natural Science Foundation of China NSFC81672767 (M.H.L), and Henan Provincial Government, China.

\section{CONFLICTS OF INTEREST}

No potential conflicts of interest were disclosed.

\section{REFERENCES}

1. Mary Photini S, Chaiwangyen W, Weber M, Al-Kawlani B, Favaro RR, Jeschke U, et al. PIM kinases 1, 2 and 3 in intracellular LIF signaling, proliferation and apoptosis in trophoblastic cells. Exp Cell Res 2017:359:275-83.

2. Keane NA, Reidy M, Natoni A, Raab MS, O'Dwyer M. Targeting the Pim kinases in multiple myeloma. Blood Cancer J 2015;5: e325.

3. Szydlowski M, Prochorec-Sobieszek M, Szumera-Cieckiewicz A, Derezinska E, Hoser G, Wasilewska D, et al. Expression of PIM kinases in Reed-Sternberg cells fosters immune privilege and tumor cell survival in Hodgkin lymphoma. Blood 2017;130: 1418-29.

4. Chen WW, Chan DC, Donald C, Lilly MB, Kraft AS. Pim family kinases enhance tumor growth of prostate cancer cells. Mol Cancer Res 2005;3:443-51.

5. Braso-Maristany F, Filosto S, Catchpole S, Marlow R, Quist J, Francesch-Domenech E, et al. PIM1 kinase regulates cell death, tumor growth and chemotherapy response in triple-negative breast cancer. Nat Med 2016;22:1303-13.

6. Nawijn MC, Alendar A, Berns A. For better or for worse: the role of Pim oncogenes in tumorigenesis. Nat Rev Cancer 2011;11: 23-34.

7. Sheldon L. Holder SAA. PIM1 kinase as a target in prostate cancer roles in tumorigenesis, castration resistance, and docetaxel resistance. Curr Cancer Drug Targets 2014;14:105-14.

8. Santio NM, Eerola SK, Paatero I, Yli-Kauhaluoma J, Anizon F, Moreau P, et al. Pim kinases promote migration and metastatic growth of prostate cancer xenografts. PLoS One 2015;10: e0130340.

9. Jimenez-Garcia MP, Lucena-Cacace A, Robles-Frias MJ, Narlik-Grassow M, Blanco-Aparicio C, Carnero A. The role of PIM1/PIM2 kinases in tumors of the male reproductive system. Sci Rep 2016;6:38079.

10. Bullock AN, Russo S, Amos A, Pagano N, Bregman H, Debreczeni JE, et al. Crystal structure of the PIM2 kinase in complex with an 
organoruthenium inhibitor. PLoS One 2009:4:e7112.

11. Qu Y, Zhang C, Du E, Wang A, Yang Y, Guo J, et al. Pim-3 is a critical risk factor in development and prognosis of prostate cancer. Med Sci Monit 2016;22:4254-60.

12. Morishita D, Katayama R, Sekimizu K, Tsuruo T, Fujita N. Pim kinases promote cell cycle progression by phosphorylating and down-regulating p27Kip1 at the transcriptional and posttranscriptional levels. Cancer Res 2008;68:5076-85.

13. Wu Y, Wang YY, Nakamoto Y, Li YY, Baba T, Kaneko S, et al. Accelerated hepatocellular carcinoma development in mice expressing the Pim-3 transgene selectively in the liver. Oncogene 2010;29:2228-37.

14. Nakano H, Hasegawa T, Saito N, Furukawa K, Mukaida N, Kojima $\mathrm{H}$, et al. Design and synthesis of an in vivo-efficacious PIM3 kinase inhibitor as a candidate anti-pancreatic cancer agent. Bioorg Med Chem Lett 2015;25:5687-93.

15. Popivanova BK, Li YY, Zheng H, Omura K, Fujii C, Tsuneyama K, et al. Proto-oncogene, Pim- 3 with serine/threonine kinase activity, is aberrantly expressed in human colon cancer cells and can prevent bad-mediated apoptosis. Cancer Sci 2007:98:321-8.

16. Lou L, Wang Y, Cui J, Yan X, Xue L, Li Y. Differential expression of Pim-3, c-Myc, and p-p27 proteins in adenocarcinomas of the gastric cardia and distal stomach. Tumour Biol 2014:35:5029-36.

17. Horiuchi D, Kusdra L, Huskey NE, Chandriani S, Lenburg ME, Gonzalez-Angulo AM, et al. MYC pathway activation in triple-negative breast cancer is synthetic lethal with CDK inhibition. J Exp Med 2012;209:679-96.

18. Shirogane T, Fukada T, Muller JM, Shima DT, Hibi M, Hirano T. Synergistic roles for Pim-1 and c-Myc in STAT3-mediated cell cycle progression and antiapoptosis. Immunity 1999;11:709-19.

19. Zhang Y, Wang Z, Li X, Magnuson NS. Pim kinase-dependent inhibition of c-Myc degradation. Oncogene 2008;27:4809-19.

20. Eilers M, Eisenman RN. Myc's broad reach. Genes Dev 2008;22: 2755-66.

21. Zippo A, De Robertis A, Serafini R, Oliviero S. PIM1-dependent phosphorylation of histone $\mathrm{H} 3$ at serine 10 is required for MYC-dependent transcriptional activation and oncogenic transformation. Nat Cell Biol 2007;9:932-44.

22. Pestell RG, Albanese C, Reutens AT, Segall JE, Lee RJ, Arnold A. The cyclins and cyclin-dependent kinase inhibitors in hormonal regulation of proliferation and differentiation. Endocr Rev 1999; 20:501-34.

23. Banerjee S, Lu J, Cai Q, Sun Z, Jha HC, Robertson ES. EBNA3C augments Pim-1 mediated phosphorylation and degradation of p21 to promote B-cell proliferation. PLoS Pathog 2014;10: e1004304.

24. Morishita D, Takami M, Yoshikawa S, Katayama R, Sato S, Kukimoto-Niino $M$, et al. Cell-permeable carboxyl-terminal p27(Kip1) peptide exhibits anti-tumor activity by inhibiting Pim-1 kinase. J Biol Chem 2011;286:2681-8.

25. Jessus C, Ozon R. Function and regulation of cdc 25 protein phosphate through mitosis and meiosis. Prog Cell Cycle Res 1995;1: 215-28.

26. Kumagai A, Dunphy WG. Binding of $14-3-3$ proteins and nuclear export control the intracellular localization of the mitotic inducer Cdc25. Genes Dev 1999:13:1067-72.

27. Leong KG, Gao WQ. The notch pathway in prostate development and cancer. Differentiation 2008;76:699-716.

28. Santio NM, Landor SK, Vahtera L, Yla-Pelto J, Paloniemi E,
Imanishi SY, et al. Phosphorylation of Notch1 by Pim kinases promotes oncogenic signaling in breast and prostate cancer cells. Oncotarget 2016;7:43220-38.

29. Yang E, Zha J, Jockel J, Boise LH, Thompson CB, Korsmeyer SJ. $\mathrm{Bad}$, a heterodimeric partner for Bcl-XL and Bcl-2, displaces Bax and promotes cell death. Cell 1995;80:285-91.

30. Zhou XM, Liu Y, Payne G, Lutz RJ, Chittenden T. Growth factors inactivate the cell death promoter BAD by phosphorylation of its BH3 domain on Ser155. J Biol Chem 2000;275:25046-51.

31. Datta SR, Katsov A, Hu L, Petros A, Fesik SW, Yaffe MB, et al. 14-3-3 proteins and survival kinases cooperate to inactivate $B A D$ by BH3 domain phosphorylation. Mol Cell 2000;6:41-51.

32. Aho TL, Sandholm J, Peltola KJ, Mankonen HP, Lilly M, Koskinen PJ. Pim-1 kinase promotes inactivation of the pro-apoptotic Bad protein by phosphorylating it on the Ser112 gatekeeper site. FEBS Lett 2004:571:43-9.

33. Jang SH, Chung HY. MYC and PIM2 co-expression in mouse bone marrow cells readily establishes permanent myeloid cell lines that can induce lethal myeloid sarcoma in vivo. Mol Cells 2012;34:201-8.

34. Yan B, Zemskova M, Holder S, Chin V, Kraft A, Koskinen PJ, et al. The PIM-2 kinase phosphorylates $\mathrm{BAD}$ on serine 112 and reverses BAD-induced cell death. J Biol Chem 2003;278:45358-67.

35. Hu XF, Li J, Vandervalk S, Wang Z, Magnuson NS, Xing PX. PIM-1-specific mAb suppresses human and mouse tumor growth by decreasing PIM-1 levels, reducing Akt phosphorylation, and activating apoptosis. J Clin Invest 2009;119:362-75.

36. Ma J, Arnold HK, Lilly MB, Sears RC, Kraft AS. Negative regulation of Pim-1 protein kinase levels by the B56beta subunit of PP2A. Oncogene 2007;26:5145-53.

37. Matikainen S, Sareneva T, Ronni T, Lehtonen A, Koskinen PJ, Julkunen I. Interferon-alpha activates multiple STAT proteins and upregulates proliferation-associated IL-2Ralpha, c-myc, and pim-1 genes in human T cells. Blood 1999;93:1980-91.

38. Peltola KJ, Paukku K, Aho TL, Ruuska M, Silvennoinen O, Koskinen PJ. Pim-1 kinase inhibits STAT5-dependent transcription via its interactions with SOCS1 and SOCS3. Blood 2004; 103:3744-50.

39. Horiuchi D, Camarda R, Zhou AY, Yau C, Momcilovic O, Balakrishnan S, et al. PIM1 kinase inhibition as a targeted therapy against triple-negative breast tumors with elevated MYC expression. Nat Med 2016;22:1321-9.

40. Zhang J, Luo X, Li H, Deng L, Wang Y. Genome-wide uncovering of STAT3-mediated miRNA expression profiles in colorectal cancer cell lines. Biomed Res Int 2014:2014:187105.

41. Huang X, Ding L, Bennewith KL, Tong RT, Welford SM, Ang KK, et al. Hypoxia-inducible mir-210 regulates normoxic gene expression involved in tumor initiation. Mol Cell 2009;35:856-67.

42. Chen LS, Redkar S, Taverna P, Cortes JE, Gandhi V. Mechanisms of cytotoxicity to Pim kinase inhibitor, SGI-1776, in acute myeloid leukemia. Blood 2011;118:693-702.

43. Kreuz S, Holmes KB, Tooze RM, Lefevre PF. Loss of PIM2 enhances the anti-proliferative effect of the pan-PIM kinase inhibitor AZD1208 in non-Hodgkin lymphomas. Mol Cancer 2015;14:205.

44. Kirschner AN, Wang J, van der Meer R, Anderson PD, FrancoCoronel OE, Kushner MH, et al. PIM kinase inhibitor AZD1208 for treatment of MYC-driven prostate cancer. J Natl Cancer Inst 2015;107:dju407.

45. Cortes J, Tamura K, DeAngelo DJ, de Bono J, Lorente D, Minden 
M, et al. Phase I studies of AZD1208, a proviral integration Moloney virus kinase inhibitor in solid and haematological cancers [published online ahead of print May 16, 2018]. Br J Cancer doi: 10.1038/s41416-018-0082-1.

46. Garcia PD, Langowski JL, Holash J, Burger M, Zang R, Zavorotinskaya T, et al. The Pan-PIM kinase inhibitor LGH447 shows activity In PIM2-dependent multiple myeloma and In AML models. Blood 2013;122:1666.

47. Raab MS, Ocio EM, Thomas SK, Günther A, Goh YT, Lebovic D, et al. Phase 1 study update of the novel pan-pim kinase inhibitor LGH447 in patients with relapsed/refractory multiple myeloma. Blood 2014;124:301.

48. Harada M, Benito J, Yamamoto S, Kaur S, Arslan D, Ramirez S, et al. The novel combination of dual mTOR inhibitor AZD2014 and pan-PIM inhibitor AZD1208 inhibits growth in acute myeloid leukemia via HSF pathway suppression. Oncotarget 2015;6:37930-47.

49. Yang $Q$, Chen LS, Neelapu SS, Gandhi V. Combination of Pim kinase inhibitor SGI-1776 and bendamustine in B-cell lymphoma. Clin Lymphoma Myeloma Leuk 2013;13 Suppl 2:S355-62.

50. Holder S, Zemskova M, Zhang C, Tabrizizad M, Bremer R, Neidigh JW, et al. Characterization of a potent and selective small-molecule inhibitor of the PIM1 kinase. Mol Cancer Ther 2007;6: 163-72.
51. Jie W, He OY, Luo BT, Zheng SJ, Kong YQ, Jiang HG, et al. Inhibition of Pim- 1 attenuates the proliferation and migration in nasopharyngeal carcinoma cells. Asian Pac J Trop Med 2012;5: 645-50.

52. Chao SW, Su MY, Chiou LC, Chen LC, Chang CI, Huang WJ. Total synthesis of Hispidulin and the structural basis for its inhibition of Proto-oncogene kinase Pim-1. J Nat Prod 2015;78:1969-76.

53. Liu K, Gao H, Wang Q, Wang L, Zhang B, Han Z, et al. Hispidulin suppresses cell growth and metastasis by targeting PIM1 through JAK2/STAT3 signaling in colorectal cancer. 2018;109:1369-81.

54. Gao H, Wang H, Peng J. Hispidulin induces apoptosis through mitochondrial dysfunction and inhibition of P13k/Akt signalling pathway in HepG2 cancer cells. Cell Biochem Biophys 2014; 69:27-34.

55. Kim DS, Sung JS, Shin ES, Ryu JS, Choi IK, Park KH, et al. Association of single nucleotide polymorphisms in PIM-1 gene with the risk of Korean lung cancer. Cancer Res Treat 2008:40:190-6.

56. Forshell LP, Li Y, Forshell TZ, Rudelius M, Nilsson L, Keller U, et al. The direct Myc target Pim3 cooperates with other Pim kinases in supporting viability of Myc-induced B-cell lymphomas. Oncotarget 2011;2:448-60. 